\title{
Adaptation and psychometric evaluation of a core competencies measure for Malaysian youth workers
}

\begin{abstract}
Core competencies in youth work refer to demonstrated capacities of quality performance that allow youth development workers to be resources for the young people, organizations and communities with whom they work. While a number of practice frameworks based on core competencies have been developed, few validated assessment measures exist to help identify professional development needs for youth workers. This article describes the adaptation and psychometric validation of a core competency assessment tool for youth work practitioners in Malaysia. A quantitative study was undertaken to validate an adapted core competency measure with a sample of 300 Malaysian youth workers. Psychometric validation included both internal consistency and construct, convergent and discriminant validity tests. Confirmatory factor analysis yielded 12 core competency sub-scales. Adequate internal consistency was achieved for each subscale along with the full measure. The findings support the validity and reliability of the core competency measure. Recommendations for application and further research are discussed.
\end{abstract}

Keyword: Youth workers; Core competencies; Professional development; Positive youth development; Measurement validation 